\title{
Factors influencing health-related quality of life in patients with Type 1 diabetes
}

\author{
A. J. N. Raymakers ${ }^{1,2^{*}}$, P. Gillespie ${ }^{1,2}$, M. C. O'Hara ${ }^{3}$, M. D. Griffin ${ }^{1}$ and S. F. Dinneen ${ }^{4,5}$
}

\begin{abstract}
Aims: Generic, preference-based measures of health-related quality of life (HRQOL) are a common input to the economic evaluation of new health technologies. As such, it is important to explore what characteristics of patients with Type 1 diabetes might impact scores on such measures.

Methods: This study utilizes baseline data from a cluster-randomized trial that recruited patients with Type 1 diabetes at six centers across Ireland. Health-related quality of life was assessed using the three-level EuroQol EQ-5D (EQ-5D) measure. Patients' responses to individual dimensions of the EQ-5D were explored. To see which patient factors influenced EQ-5D scores, multivariate regression analysis was conducted with EQ-5D scores as the outcome variable.
\end{abstract}

Results: Data was available for 437 Type 1 diabetes patients. The median age of these patients was 40 (IQR: 31-49) years and 53.8\% were female. Overall, patients reported a high HRQoL based on EQ-5D scores (0.87 (SD: 0.19). Fifty-four percent of patients reported a perfect HRQoL. For those that reported problems, the most common dimension was the anxiety/ depression dimension of the EQ-5D (29.6\%). In the multivariate regression analysis, self-reported mental illness (- 0.22 (95\% Cl: $-0.34,-0.10))$ and being unemployed $(-0.07(95 \% \mathrm{Cl}:-0.13,-0.02))$ were negatively associated with EQ-5D scores $(p<0.05)$. The influence of self-reported mental illness was persistent in sensitivity analyses.

Conclusions: The study results indicate that patients with Type 1 diabetes report a high HRQoL based on responses to the EQ-5D. However, there are a substantial number of Type 1 diabetes patients that report problems in the anxiety/ depression dimension, which may provide avenues to improve patients' HRQoL.

Trial registration: Current Controlled Trials ISRCTN79759174.

\section{Introduction}

The global incidence of Type 1 diabetes has been rising and is predicted to further increase in the foreseeable future [1]. Commensurate with this increase is the development and availability of new technologies for the monitoring and treatment of the disease [2]. Emerging technologies will need to demonstrate their relative value, compared to existing technologies, in order to be reimbursed by the relevant body. Economic evaluation is a method for making such comparisons, whereby the costs and benefits of new technologies, compared to the standard of care, are simultaneously considered [3]. Generic, preference-based measures of health-related quality of life (HRQoL) are often used to assess these benefits in economic evaluation and,

\footnotetext{
* Correspondence: adam.raymakers@nuigalway.ie

${ }^{1}$ CÚRAM Centre for Research in Medical Devices, National University of

Ireland Galway, Galway, Ireland

${ }^{2}$ Health Economics and Policy Analysis Centre, National University of Ireland

Galway, Galway, Ireland

Full list of author information is available at the end of the article
}

thus, play a key role in the reimbursement of health interventions. As such, it is important to understand factors that might influence patients' scores on these measures.

Existing literature for patients with Type 2 diabetes has found that obesity and the presence of diabetes-related complications were significant factors in determining patients EQ-5D scores [4]. For women with gestational diabetes, Danyliv et al. [5] found no statistically significant associations with patient characteristics and EQ-5D scores, aside from smoking status (specifically, being a previous smoker). In a study population of patients with Type 1 diabetes between 8 and 17 years of age, a significant association was estimated between poor glycemic control with both depression and HRQoL [6]. Poor glycemic control [7] and hyperglycemic symptoms [8] were also associated with reduced HRQoL, measured using the EQ-5D in adult patients, even after adjustment for diabetes-related complications [9]. Similar to results reported in patients with Type 2 diabetes, previous evidence suggests that diabetes-related 
complications are significantly and negatively related to EQ-5D index scores in adults with Type 1 diabetes [10].

Therefore, the objective of this study is to explore associations between those factors that influence HRQoL, as measured by the EQ-5D and EQ-VAS, in patients with Type 1 diabetes.

\section{Methods}

This study used baseline data from the Irish Dose Adjustment for Normal Eating (DAFNE) cluster-randomized trial which compared structured curriculum-based group education follow-up with individual follow-up for patients with Type 1 diabetes. Full details are the trial are reported in the study protocol [11], clinical study [12], and cost-effectiveness analysis [13] Additional file 1.

\section{Health-related quality of life measurement}

For this study, the outcomes of interest are the 3-level version of the EuroQol 5-dimension instrument (hereafter, the 'EQ-5D'), and the secondary outcome, the EuroQol Visual Analogue Scale (EQ-VAS). The EQ-VAS accompanies the EQ-5D questionnaire and is a visual analogue scale for which respondents are directed to indicate their perceived HRQoL on that particular day (scale 0-100). The EQ-5D is a generic, preference-based measure of HRQoL consisting of five dimensions, each with three levels [14]. These five dimensions include: mobility, self-care, usual activities, pain/discomfort, and anxiety/depression. Each dimension has three effective levels: no problems, some problems, extreme problems. The EQ-5D responses were then used to compute a utility score which ranges from -0.594 to 1 . Where ' 1 ' represents a state of 'perfect' health, ' 0 ' is equal to death, and health states below ' 0 ' are considered to be worse than death [15].

\section{Statistical analysis}

We examined the distribution of EQ-5D index scores and EQ-VAS scores which revealed a skewed distribution for the EQ-5D scores, similar to what has been reported elsewhere [16]. EQ-VAS scores approximated a normal distribution. Univariate linear regression analyses were conducted using EQ-5D index scores and EQ-VAS scores as the outcome variable. Covariates were included in the multivariate model using a threshold of inclusion of $p<0.2$ in these univariate models. Due to distributional concerns about EQ-5D scores, and concerns about the interpretability of results in a linear regression framework, we estimated the linear regression models using robust standard errors (also known as White-Huber standard errors) [17]. A sensitivity analysis was also performed, given these distributional concerns with EQ-5D scores, whereby a binary outcome variable was created for those reporting 'any problems' and those reporting 'no problems' in EQ-5D scores to explore whether the same associations existed in a logistic regression framework. Finally, we explored individual domain scores to determine whether covariates were significantly associated with specific domains of the EQ$5 \mathrm{D}$, again by collapsing the responses into 'any problems' and 'no problems'. All analyses were conducted using the statistical package ' $R$ ' (version 3.2.3).

\section{Results}

This trial consisted of 437 patients with Type 1 diabetes from 6 centres across Ireland (including one site in Northern Ireland). The median age of these patients was 40 (IQR: $31-49$ ) and 53.8\% were female. Further details of the study patients are available in Table 1. Fifty-four percent of patients reported themselves as being in perfect health based on the EQ-5D index score. Only one patient reported a value of less than 0 . The mean EQ-5D score and mean EQ-VAS score were 0.87 (SD: 0.19) and 71.5 (SD: 16.8), respectively.

\section{Individual EQ-5D dimensions}

With regard to individual dimension scores, patients reported very few problems in the mobility and self-care dimensions (89.7\% and 95.2\%, respectively). In the dimensions reporting usual activities, pain/discomfort, and anxiety/depression, the number of patients reporting no problems was smaller $(81.0 \%, 78.3 \%$, and $70.4 \%$, respectively). Figure 1 provides more detail on the scores for each dimension.

\section{Multivariate regression results}

Multivariate regression results for EQ-VAS scores (scale 0100 ) indicated that age, $\mathrm{HbA}_{1 \mathrm{c}}$, disease duration, and obesity (BMI $\geq 30 \mathrm{~kg} / \mathrm{m}^{2}$ ) were significantly associated with patients' HRQoL (all $p<0.05$ ). Patients' age had the smallest impact and obesity had the largest impact on EQ-VAS scores (0.21 ((95\% CI: 0.04-0.39) and - 11.8 (95\% CI: -17.2, - 6.3), respectively. Multivariate regression models were estimated to explore associations with EQ-5D index scores found that self-reported mental illness, and employment status, were significantly and negatively associated with EQ-5D index scores ( $p<0.05$ for both). Self-reported mental illness was associated with a reduction in EQ-5D index scores (scale $0-1)$ of approximately -0.22 (95\% CI: $-0.34,-0.10$ ) and being unemployed was associated with a reduction of approximately -0.07 (95\% CI: $-0.13,-0.02)$ (Table 2). As a sensitivity analysis, EQ-5D respondents were categorized as having 'no problems' (EQ-5D equal to 1 ) or reporting any 'problems' (EQ-5D score less than 1) and a multivariate logistic regression analysis was conducted. The results of this analysis suggest that selfreported mental illness had the largest and statistically significant effect on reporting of problems with EQ-5D scores; that is, patients with self-reported mental illness were 8 times more likely to report problems in EQ-5D 
Table 1 Characteristics of the study participants

\begin{tabular}{|c|c|}
\hline Characteristic & Value \\
\hline Age & 40.8 (SD: 11.7) \\
\hline Female & $235(53.8 \%)$ \\
\hline $\begin{array}{l}\text { Completed 3rd Level } \\
\text { Education }\end{array}$ & $178(48.0 \%)$ \\
\hline Single & $142(37.6 \%)$ \\
\hline Employed & $297(78.4 \%)$ \\
\hline Smoking History ${ }^{\mathrm{a}}$ & $174(45.6 \%)$ \\
\hline Body Mass Index (BMI) kg/m² & 26.0 (SD: 4.1) \\
\hline Years Since Diagnosis & 15.9 (SD: 10.8) \\
\hline $\mathrm{HbA}_{1 \mathrm{c}}(\%)$ & $8.3 \%$ (SD: 1.4) \\
\hline $\mathrm{HbA}_{1 \mathrm{c}}(\mathrm{mmol} / \mathrm{mol})$ & 67 (SD: 8) \\
\hline Systolic BP mg/Hg & 124.9 (SD: 18.9) \\
\hline Diastolic BP mg/Hg & 74.1 (SD: 10.9) \\
\hline Complications $^{a}$ & $93(21.4 \%)$ \\
\hline EQ-VAS ${ }^{b}$ & 71.5 (SD: 16.8) \\
\hline$E Q-5 D^{c}$ & 0.87 (SD: 0.19) \\
\hline \multicolumn{2}{|l|}{$\begin{array}{l}\text { Individual Dimensions } \\
\text { of the EQ-5D }\end{array}$} \\
\hline \multicolumn{2}{|l|}{ Mobility } \\
\hline No Problems & $392(89.7 \%)$ \\
\hline Some Problems & $35(8.0 \%)$ \\
\hline Extreme Problems & $0(0 \%)$ \\
\hline \multicolumn{2}{|l|}{ Self-Care } \\
\hline No Problems & $416(95.2 \%)$ \\
\hline Some Problems & $7(1.6 \%)$ \\
\hline Extreme Problems & $0(0 \%)$ \\
\hline \multicolumn{2}{|l|}{ Usual Activities } \\
\hline No Problems & $354(81.0 \%)$ \\
\hline Some Problems & $70(16.3 \%)$ \\
\hline Extreme Problems & $3(0.7 \%)$ \\
\hline \multicolumn{2}{|l|}{ Pain/Discomfort } \\
\hline No Problems & $335(78.3 \%)$ \\
\hline Some Problems & $81(18.9 \%)$ \\
\hline Extreme Problems & $10(2.3 \%)$ \\
\hline \multicolumn{2}{|l|}{ Anxiety/Depression } \\
\hline No Problems & $295(70.4 \%)$ \\
\hline Some Problems & $118(28.2 \%)$ \\
\hline Extreme Problems & $6(1.4 \%)$ \\
\hline
\end{tabular}

a Patients reporting complications, including: neuropathy, foot ulcer, amputation, cardiovascular disease, proteinuria, retinopathy, blindness. ${ }^{\mathrm{b}}$ The EQ-VAS scale is 0 to 100 . ${ }^{~}$ The EQ-5D scale is -0.594 to 1 . BMI Body Mass Index, $H b A_{1 c}$ glycated hemoglobin, HADS Hospital Anxiety and Depression Score, $B P$ Blood pressure, EQ-5D EuroQol 5-Dimension, EQ-VAS Visual Analogue Component of the EQ-5D instrument scores $(p=0.049)$. Mental illness was significantly associated with an increased likelihood of reporting problems in both the 'Pain/Discomfort' and 'Anxiety/Depression' domains $(p<0.05)$, and was not significantly associated with other domains. In addition, being unemployed was associated with an increased likelihood of reporting problems in the 'Mobility, 'Self-Care', and 'Pain/Discomfort' domains ( $p$ $<0.05)$.

\section{Discussion}

This study sought to explore associations between characteristics of Type 1 diabetes patients, with scores from a generic, preference-based measure of HRQoL, the EQ-5D. The importance of performing such exploratory analyses and understanding associations between patient characteristics and EQ-5D scores is two-fold. First, EQ-5D scores are often used in economic evaluations that inform reimbursement decisions for new health interventions. As such, it is important to understand the individual patient characteristics which form the basis for these scores. Second, individual EQ-5D dimension scores can be used to identify which dimensions have the greatest impact on patients' overall HRQoL and these dimension scores might allow clinicians to understand where improvements could be made in patient care. The results of this study suggest many Type 1 diabetes patients do not report that their disease has an impact on their individual HRQoL, but, for a subset of Type 1 diabetes patients, mental illness (self-reported) has a statistically significant negative impact on HRQoL.

The results of the EQ-5D presented in this study might suggest that this generic measure of preference-based HRQoL may not be sufficiently sensitive to capture the impact of Type 1 diabetes on patients. However, it is worth noting that a five level version of the EuroQol instrument (EQ-5D-5L) has been developed to address the issue of sensitivity (as well as other issues) [18]. The descriptive system associated with the EQ-5D-5L is an obvious improvement to the EQ-5D-3L, but there remain issues about the tariffs used to estimate index scores, and how these calculations impact the results of cost-utility analyses [19]. Accordingly, there has been some reluctance from decision-making bodies to move toward recommending the EQ-5D-5L as a part of reimbursement submissions [20]. Similarly, the results reported in this study may have implications for the economic evaluation and reimbursement of new health technologies for individuals with diabetes. For example, if a new technology is put forward to be evaluated for reimbursement, unless it has the ability of improve patients' mental health, and thus improve patients' responses in the respective domains, it may not show any benefit for a given cost, and is potentially unlikely to be reimbursed. It also suggests that interventions targeting patients' mental health are an avenue to improve their HRQoL. This result aligns with findings by 


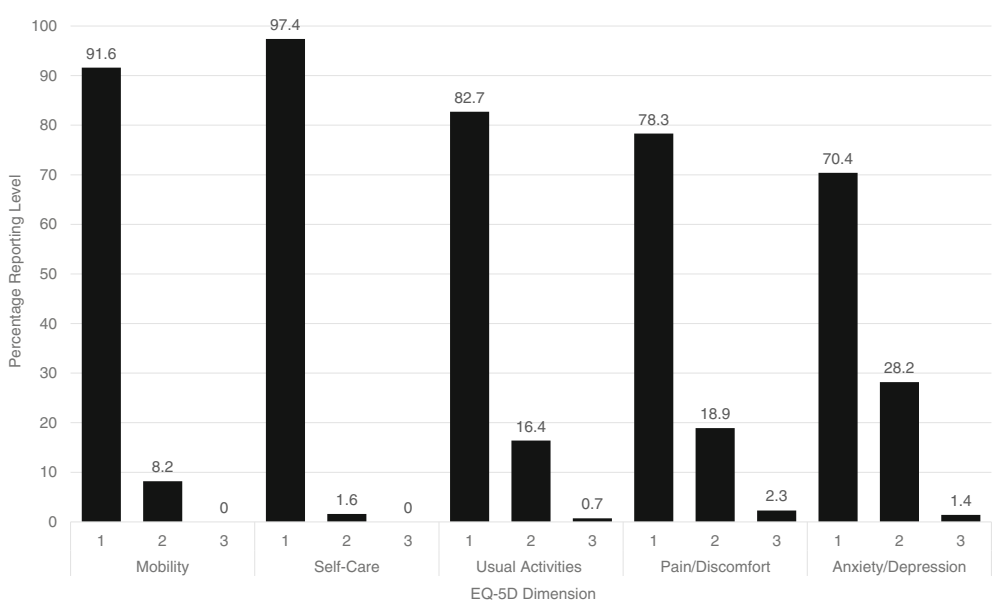

Fig. 1 Percentage of patients reporting each level of EQ-5D dimension scores. Level 1 represents 'No Problems', level 2 'Some Problems', and level 3 'Extreme Problems'

Byrne et al. [21], whereby their analysis suggested that patients with higher levels of diabetes-related anxiety were most likely to benefit from support programs in terms of improved overall quality of life.

This study has several limitations. First, we used cross-sectional data from a previously completed trial to evaluate associations between HRQoL and potential influential factors. While it is certainly advantageous to use longitudinal data, we emphasize that this study was

Table 2 Regression analysis of baseline data with EQ-5D index scores (scale 0-1) as the outcome variable

\begin{tabular}{|c|c|c|c|c|}
\hline & Estimate & $95 \% \mathrm{LL}$ & $95 \%$ UL & $p$ value \\
\hline Age & -0.001 & -0.004 & 0.001 & 0.132 \\
\hline Gender (Male) & -0.011 & -0.052 & 0.029 & 0.568 \\
\hline Unemployed & -0.073 & -0.130 & -0.016 & 0.039 \\
\hline Obese $^{a}$ & -0.046 & -0.107 & 0.014 & 0.167 \\
\hline Medical Card & -0.040 & -0.093 & 0.014 & 0.177 \\
\hline Marital Status (Single) & 0.011 & -0.032 & 0.055 & 0.580 \\
\hline \multicolumn{5}{|l|}{ Education $^{\mathrm{b}}$} \\
\hline Complete 2nd level & 0.010 & -0.057 & 0.077 & 0.801 \\
\hline Complete 3rd level & 0.014 & -0.052 & 0.080 & 0.721 \\
\hline Complications $^{c}$ & -0.020 & -0.073 & 0.032 & 0.407 \\
\hline Disease Duration & -0.002 & -0.004 & 0.000 & 0.095 \\
\hline Mental Illness ${ }^{d}$ & -0.219 & -0.337 & -0.100 & 0.017 \\
\hline High Blood Pressure & -0.009 & -0.063 & 0.044 & 0.740 \\
\hline $\mathrm{HbA}_{1 \mathrm{c}}(\%)$ & -0.018 & -0.033 & -0.002 & 0.076 \\
\hline Heart Disease $^{d}$ & 0.013 & -0.103 & 0.129 & 0.886 \\
\hline Chest/Lung Disease ${ }^{d}$ & 0.051 & -0.073 & 0.176 & 0.491 \\
\hline
\end{tabular}

${ }^{\mathrm{a}} \mathrm{BMI} \geq 25 \mathrm{~kg} / \mathrm{m}^{2}$. ${ }^{\mathrm{b}}$ Reference Category: did not complete second level education. ' Patients reporting complications, including: neuropathy, foot ulcer, amputation, cardiovascular disease, proteinuria, retinopathy, blindness. ${ }^{d}$ Categorical variable (Yes $=1, \mathrm{No}=0$ ), self-reported. $L$ L Lower limit of 95\% confidence interval. UL Upper limit of $95 \%$ confidence interval meant to be exploratory and form a basis for future research. Second, EQ-5D scores were asymmetrically distributed and, as such, pose concerns for standard regression techniques. However, we believe the techniques used to minimize the impact of these concerns are appropriate, particularly in the context of an exploratory study. Third, the presence of mental illness (and other comorbidities) was based on self-report. We acknowledge that a more robust ascertainment of clinical history would be an improvement, as would greater specificity as to the nature of mental illness.

\section{Conclusions}

Type 1 diabetes patients enrolled in this study reported a high health-related quality of life, with over half of patients reporting 'perfect' health based on EQ-5D responses. However, in those that did report problems, the most common were reported in the 'Anxiety/Depression' dimension. Similarly, multivariate regression analysis suggested that self-reported mental illness had the most substantial impact on EQ-5D scores. The results of this study demonstrate the importance of exploring individual dimensions of EQ-5D scores and the findings may also imply that clinicians treating patients with Type 1 diabetes should be particularly mindful of their patients mental well-being.

\section{Additional files}

Additional file 1: CONSORT Flow Diagram for the original cluster randomized controlled trial. (TIFF $6514 \mathrm{~kb}$ )

\section{Abbreviations}

BMI: Body mass index; Cl: Confidence interval; DAFNE: Dose Adjustment for Normal Eating; EQ-5D-3L: EuroQol 5-dimesion 3-level; HbA 1 : Glycated hemoglobin; HRQoL: Health-related quality of life; IQR: Interquartile range; SD: Standard deviation; VAS: Visual analogue scale 


\section{Acknowledgements}

We wish to thank the all of the patients and DAFNE educators involved in this study and the Irish DAFNE Study Steering Group: Sean Dinneen (Principal Investigator), Mary Clare O'Hara (Project Manager), Lisa Daly (former Project Manager), Simon Heller, C Hamish Courtney, Donal O'Shea, Diarmuid Smith, Colm McGurk, Kathy Murphy, Eamon O'Shea, Dympna Casey, Julia Lawton, Florence Findlay White, John Newell, Molly Byrne, Paddy Gillespie, Marie Clark, and Debbie Cooke.

\section{Funding}

The Irish DAFNE RCT was funded by a Health Research Board Health, Services Research and Development Award. Support for this work was also provided by Science Foundation Ireland and the European Regional Development Fund (Grant Number 13/RC/2073). The funders played no part in the design, data analysis, manuscript preparation, nor publication decisions.

\section{Availability of data and materials}

Please contact the corresponding author for data requests.

\section{Authors' contributions}

$A R, M G$, and PG conceptualized the study. MCOH and SD provided critical insight into the clinical area. All authors were involved in interpreting the study results and contributed to the preparation of the manuscript and subsequently approved the final version.

\section{Ethics approval and consent to participate}

Ethical approval was obtained from the Research Ethics Committee of Galway University Hospitals (CA 19), from COREC (currently: National Research Ethics Service) Northern Ireland (06/NIR01/126). All study participants provided informed consent prior to enrolment in the trial.

\section{Consent for publication}

Not applicable.

\section{Competing interests}

The authors declare that they have no competing interests.

\section{Publisher's Note}

Springer Nature remains neutral with regard to jurisdictional claims in published maps and institutional affiliations.

\section{Author details}

${ }^{1}$ CÚRAM Centre for Research in Medical Devices, National University of Ireland Galway, Galway, Ireland. ${ }^{2}$ Health Economics and Policy Analysis Centre, National University of Ireland Galway, Galway, Ireland. ${ }^{3}$ Research and Development, Health Services Executive, Health and Wellbeing Division, Galway, Ireland. ${ }^{4}$ School of Medicine, Clinical Science Institute, National University of Ireland Galway, Galway, Ireland. ${ }^{5}$ Endocrinology and Diabetes Centre, Galway University Hospital, Galway, Ireland.

Received: 16 June 2017 Accepted: 16 January 2018

Published online: 02 February 2018

\section{References}

1. Patterson CC, Dahlquist GG, Gyürüs E, Green A, Soltész G, Group ES, et al. Incidence trends for childhood type 1 diabetes in Europe during 1989-2003 and predicted new cases 2005-20: a multicentre prospective registration study. Lancet. 2009;373(9680):2027-33.

2. Atkinson MA, Eisenbarth GS, Michels AW. Type 1 diabetes. Lancet. 2014; 383(9911):69-82

3. Drummond MF, Sculpher MJ, Claxton K, Stoddart GL, Torrance GW. Methods for the economic evaluation of health care Programmes. Oxford: University Press; 2015. p. 461.

4. Redekop WK, Koopmanschap MA, Stolk RP, Rutten GE, Wolffenbuttel BH, Niessen LW. Health-related quality of life and treatment satisfaction in Dutch patients with type 2 diabetes. Diabetes Care. 2002;25(3):458-63.

5. Danyliv A, Gillespie P, O'Neill C, Noctor E, O'Dea A, Tierney M, et al. Health related quality of life two to five years after gestational diabetes mellitus: cross-sectional comparative study in the ATLANTIC DIP cohort. BMC Pregnancy Childbirth. 2015; 15(1):274. [cited 2016 Dec 16] Available from: http://bmcpregnancychildbirth. biomedcentral.com/articles/10.1186/s12884-015-0705-y
6. Hassan K, Loar R, Anderson BJ, Heptulla RA. The role of socioeconomic status, depression, quality of life, and glycemic control in type 1 diabetes mellitus. J Pediatr. 2006;149(4):526-31.

7. Ozcan S, Amiel SA, Rogers H, Choudhary P, Cox A, de Zoysa N, et al. Poorer glycaemic control in type 1 diabetes is associated with reduced selfmanagement and poorer perceived health: a cross-sectional study. Diabetes Res Clin Pract. 2014;106(1):35-41.

8. Hart HE, Bilo HJG, Redekop WK, Stolk RP, Assink JH, Jong BM. Quality of life of patients with type I diabetes mellitus. Qual Life Res. 2003;12(8):1089-97.

9. McQueen RB, Ellis SL, Maahs DM, Anderson HD, Nair KV, Libby AM, et al. Association between Glycated hemoglobin and health utility for type 1 diabetes. Patient. 2014;7(2):197-205.

10. Solli O, Stavem K, Kristiansen IS. Health-related quality of life in diabetes: the associations of complications with EQ-5D scores. Health Qual Life Outcomes. 2010;8(1):1.

11. The Irish DAFNE Study Group, Dinneen SF, O' Hara MC, Byrne M, Newell J, Daly $L$, et al. The Irish DAFNE study protocol: a cluster randomised trial of group versus individual follow-up after structured education for type 1 diabetes. Trials. 2009;10(1):88. [cited 2016 Dec 16] Available from: http:// trialsjournal.biomedcentral.com/articles/10.1186/1745-6215-10-88

12. Dinneen SF, O'Hara MC, Byrne M, Smith D, Courtney $C H$, McGurk C, et al. Group follow-up compared to individual clinic visits after structured education for type 1 diabetes: a cluster randomised controlled trial. Diabetes Res Clin Pract. 2013;100(1):29-38.

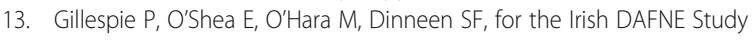
Group. Cost effectiveness of group follow-up after structured education for type 1 diabetes: a cluster randomised controlled trial. Trials. 2014;15(1):227.

14. The EuroQol Group. EuroQol - a new facility for the measurement of healthrelated quality of life. Health Policy. 1990;16(3):199-208.

15. Dolan P, Gudex C, Kind P, Williams A. The time trade-off method: results from a general population study. Health Econ. 1996;5(2):141-54.

16. Parkin $D$, Devlin $N$, Feng $Y$. What determines the shape of an EQ-5D index distribution? Med Decis Making. 2016;36(8):941-51.

17. Gujarati DN. Basic econometrics. 4th ed. Boston: McGraw Hill; 2003. p. 1002.

18. Herdman M, Gudex C, Lloyd A, Janssen M, Kind P, Parkin D, et al. Development and preliminary testing of the new five-level version of EQ-5D (EQ-5D-5L). Qual Life Res. 2011;20(10):1727-36.

19. Alava MH, Wailoo A, Grimm S, Pudney S, Gomes M, Sadique Z, et al. EQ-5D-5L versus EQ-5D-3L: The Impact on Cost-Effectiveness in the United Kingdom. Value Health. 2017. Available from: http://www.valueinhealthjournal.com/ article/S1098-3015(17)33410-1/fulltext. Accessed 15 Dec 2017.

20. National Institute for Health and Care Excellence (NICE). NICE position statement on use of the EQ-5D-5L valuation set. 2017.

21. Byrne M, Newell J, Coffey N, O' Hara MC, Cooke D, Dinneen SF. Predictors of quality of life gains among people with type 1 diabetes participating in the dose adjustment for normal eating (DAFNE) structured education programme. Diabetes Res Clin Pract. 2012;98(2):243-8. 